\title{
PEMERIKSAAN IVA TEST PADA WANITA USIA SUBUR DI DESA SIMATUPANG KECAMATAN MUARA KABUPATEN TAPANULI UTARA
}

\author{
Hetty WA Panggabean ${ }^{1}$; Marni Siregar ${ }^{2}$ \\ ${ }^{1,2}$ Prodi DIII Kebidanan Tarutung Poltekkes Kemenkes Medan
}

Korespondensi : hettypanggabean54@gmail.com

\begin{abstract}
Background. Cervical cancer, still in the second position of malignancy after breast cancer, is estimated, cervical cancer affects as many as 500,000 women each year. In Indonesia, there were 14,368 cases of cervical cancer in 2019, 7,297 $(50 \%)$ of that number died, and the prevalence of cervical cancer cases was 10,823 people per year. Cervical cancer cases in Indonesia are exacerbated by the number of cases nearly $70 \%$ are known and come to health workers or health facilities at an advanced stage. The majority of women diagnosed with cervical cancer usually do not do early detection (screening), some do not follow up on examinations or treatment after finding abnormal results. Purpose. PKM activities increase public knowledge, in this case the mother, as well as participate in the IVA test so that it is detected early using the IVA test. Method. The activity begins with coordination with the Muara Public Health Center and coordinating midwives, the Village Head, Village Midwives and Cadres regarding socialization, counseling and the implementation of the IVA Test as a strategy to get participants. Result. The results obtained were 66 women of childbearing age regardless of age up to the age of 45 who had participated in the examination. The results of the examination were suspected by 14 people $(21.21 \%)$ and negative as many as 52 people (78.78\%). Conclusion. The knowledge of women of childbearing age about the IVA Test is still lacking, there are even women of childbearing age who are not present to take the IVA Test, even though the counseling is present. Knowledge of the IVA Test still needs to be followed up, so that women of childbearing age have their own awareness, as early detection of cervical cancer, thereby reducing the rate of maternal mortality.
\end{abstract}

Keywords: cervical cancer, IVA test, women of childbearing age 


\begin{abstract}
ABSTRAK
Latar Belakang. Kanker serviks, masih menempati posisi kedua terbanyak pada keganasan setelah kanker payudara, diperkirakan, kanker serviks diderita perempuan sebanyak 500.000 wanita setiap tahunnya. Di Indonesia kasus kanker serviks tahun 2019 sebanyak 14,368 orang, dari jumlah itu meninggal dunia sebanyak 7,297 (50 \%) dari jumlah kasus yang ada, dan prevalensi kasus kanker serviks sebanyak 10,823 orang per tahun. Kasus kanker serviks di Indonesia diperburuk dengan banyaknya kasus hampir $70 \%$ diketahui dan datang ke petugas kesehatan atau fasilitas kesehatan pada stadium lanjut. Mayoritas wanita yang terdiagnosa kanker serviks biasanya tidak melakukan deteksi dini (Skrining), ada juga yang tidak menindaklanjuti pemeriksaan maupun pengobatan setelah ditemukan hasil yang abnormal. Tujuan. Kegiatan PKM meningkatkan pengetahuan masyarakat dalam hal ini ibu sekaligus ikut serta dalam pemeriksaan IVA test sehinga secara dini terdeteksi dengan menggunakan IVA test. Metode. Kegiatan diawali dengan koordinasi dengan Puskesmas Muara dan bidan koordinator, Kepala Desa, Bidan Desa dan Kader tentang sosialisasai, penyuluhan dan pelaksanaan pemeriksaan IVA Test sebagai strategi untuk mendapatkan peserta. Hasil. Hasil yang didapat 66 orang wanita usia subur tanpa memandang usia sampai usia 45 telah ikut dilakukan pemeriksaan, Hasil pemeriksaan diperoleh dengan dicurigai 14 orang $(21,21 \%)$ dan negatif sebanyak 52 orang (78,78 \%). Simpulan. Pengetahuan wanita usia subur akan IVA Test masih kurang, bahkan ada wanita usia subur yang tidak hadir untuk mengikuti pemeriksaan IVA Test, walaupun dalam penyuluhan hadir. Pengetahuan akan IVA Test masih perlu ditindak lanjuti, sehingga wanita usia subur memiliki kesadararn sendiri, sebagai deteksi dini akan kanker serviks, sehingga mengurangi agka kematian ibu.
\end{abstract}

Kata kunci: kanker serviks, IVA test, wanita usia subur

\title{
PENDAHULUAN
}

Kanker serviks adalah salah satu penyakit ganas yang menyerang perempuan. Kanker serviks merupakan keganasan yang berasal dari serviks. Serviks merupakan sepertiga bagian bawah uterus, berbentuk silindris, menonjol dan berhubungan dengan vagina melalui ostium uteri eksternum. Kanker serviks, masih menenpati posisi kedua terbanyak pada keganasan setelah kanker payudara, diperkirakan, kanker serviks diderita perempuan sebanyak 500.000 wanita setiap tahunnya.

Tingginya angka kejadian dan angka kematian akibat kanker ini menjadi momok yang menakutkan bagi tiap perempuan. Pada tahun 2010 estimasi jumlah 
insiden kanker serviks adalah 454.000 kasus Data ini didapatkan dari registrasi kanker berdasarkan populasi, registrasi data vital, dan data otopsi verbal dari 187 negara dari tahun 1980 sampai 2010. Per tahun insiden dari kanker serviks meningkat 3.1\% dari 378.000 kasus pada tahun 1980. Ditemukan sekitar 200.000 kematian terkait kanker serviks, dan 46.000 diantaranya adalah wanita usia 15-49 tahun yang hidup di negara sedang berkembang.

Di Indonesia kasus kanker serviks tahun 2019 sebanyak 14,368 orang, dari jumlah itu meninggal dunia sebanyak 7,297 ( 50 \%) dari jumlah kasus yanag ada, dan prevalensi kasus kanker serviks sebanyak 10,823 orang per tahun. Kasus kanker serviks di Indonesia diperburuk dengan banyaknya kasus hampir $70 \%$ diketahui dan datang ke petugas kesehatan atau fasilitas kesehatan pada stadium lanjut. Mayoritas wanita yang terdiagnosa kanker serviks biasanya tidak melakukan deteksi dini (skrining), ada juga yang tidak menindaklanjuti pemeriksaan maupun pengobatan setelah ditemukan hasil yang abnormal.

Saat ini Indonesia berada dalam situasi double burden penyakit yang merupakan suatu kondisi dimana mengalami 2 (dua) permasalahan penyakit sekaligus yaitu penyakit menular dan penyakit tidak menular. Dalam dua dekade terakhir terjadi transisi epidemiologis yaitu kecenderungan meningkatnya prevalensi penyakit menular yang diikuti pula dengan peningkatan prevalensi penyakit tidak menular, salah satunya kanker serviks. Melihat hal ini, diperlukan strategi untuk mengendalikan penyakit tersebut yaitu dengan melakukan deteksi dini sebagai upaya preventif.

Upaya preventif kanker serviks dengan 2 (dua) cara yaitu secara primer dan sekunder. Upaya preventif secara primer adalah pencegahan faktor risiko, deteksi dini, surveilans epidemilogi, dan penyebaran informasi mencegah faktor resiko terjadinya kanker serviks dan vaksinasi. Upaya preventif secara sekunder dengan melakukan skrining untuk mendeteksi perubahan pada serviks secara dini sebelum berkembang menjadi kanker sehingga dapat disembuhkan dengan segera. 
Salah satu cara deteksi dini kanker serviks yang dapat dilakukan dengan metode Inspeksi Visual Asam Asetat. (IVA) selanjutnya disebut IVA Test.

IVA Test sebuah pemeriksaan yang sangat sederhana, mudah dijangkau karena bisa dilakukan oleh Bidan di wilayah Wanita Usia Subur (WUS) serta dengan harga yang murah. Metode pemeriksaan dengan mengoles serviks atau leher rahim dengan asam asetat. Kemudian diamati apakah ada kelainan seperti area berwarna putih. Jika tidak ada perubahan warna, maka dapat dianggap tidak ada infeksi pada serviks. Walaupun murah dan terjangkau tetapi pada kenyataannya skrining dengan IVA Test tetap rendah

Survey pendahuluan yang dilakukan di Desa Simatupang Kecamatan Muara diperoleh data ada sebanyak 66 orang WUS yaitu wanita yang sudah menikah dan usia maksimal 45 tahun. Dari 66 WUS tersebut dilakukan anamnesa sehingga didapatkan 9 (sembilan) orang belum pernah melakukan pemeriksaan IVA Test dimana 5 (lima) orang mengatakan tidak tahu, 2 (dua) orang mengatakan malu dan 2 (dua) orang mengatakan merasa takut. Berdasarkan uraian dan hasil survey di atas, peneliti tertarik melakukan pengabdian kepada masyarakat (PKM) khususnya WUS dengan melakukan pemeriksaan IVA Tes di Desa Simatupang Kecamatan Muara Kabupaten Tapanuli Utara Tahun 2019.

\section{METODE}

Berdasarkan analisis masalah yang diperoleh sesuai dengan hasil anamnesa pendahuluan kepada WUS maka dapat teridentifikasi masalah rendahnya skrining IVA Test pada WUS yaitu kurangnya pengetahuan dan sikap yang merasa malu serta rasa takut. Penyelesaian masalah yang akan dilakukan yaitu dengan Tri Darma Perguruan Tinggi dalam hal ini adalah PKM yaitu WUS di Desa Simatupang Kecamatan Muara Kabupaten Tapanuli Utara. Untuk meningkatkan pengetahuan WUS dilakukan penyuluhan dan untuk deteksi dini akan dilakukan pemerikasaan IVA Test. 
Tahap persiapan kegiatan, diawali mengurus izin PKM kemudian koordinasi dengan Kepala dan Bidan Koordinator di Puskesmas Muara, Camat Muara, Kepala Desa, Bidan dan Kader Desa Simatupang. Koordinasi dilakukan untuk menentukan tanggal pelaksanaan dan agar dapat menghadirkan WUS di Desa Simatupang saat penyuluhan dan pemeriksaan IVA Test. Selanjutnya melakukan survey lapangan (lokasi posyandu) untuk penjajakan tempat pelaksanaan penyuluhan dan pemeriksaan IVA test di Poskesdes Simatupang. Melakukan persiapan tempat yang nyaman yang digunakan melakukan penyuluhan dan pemeriksaan IVA test melalui koordinasi dengan bidan koordinator dan bidan desa.

Tahap pelaksanaan dengan 2 (dua) tahap yaitu penyuluhan dan pemeriksaan IVA Test. Penyuluhan dilakukan dengan cara menyajikan materi tentang pengertian kanker serviks, faktor resiko terjadinya kanker serviks, gejala kanker serviks, proses terjadinya kanker serviks, deteksi dini kanker serviks, cara pencegahannya dan Pemeriksaan IVA Test. Saat penyuluhan dilakukan dengan ceramah, memberikan kesempatan kepada WUS untuk bertanya dan disesi terakhir penyuluh memberikan umpan balik. Media yang digunakan saat penyuluhan adalah powerpoint dan leaflet. Hal ini bertujuan untuk memudahkan WUS memahami materi penyuluhan. Tahap kedua adalah tahap pemeriksaan IVA Test. Sebelum melakukan pemeriksaan IVA Test terlebih dahulu diberikan informed consent yang selanjutnya penandatanganan format informed consent, persiapan alat dan bahan serta pemeriksaan IVA Test kepada WUS.

\section{HASIL DAN PEMBAHASAN}

\section{Hasil}

Kegiatan PKM ini telah dilaksakan di Poskesdes Simatupang Kecamatan Muara pada tanggal pada tanggal 15 - 17 Mei 2019 dengan pembukaan dihadiri oleh Kepala dan Bidan Koordinator Puskesmas Muara, Kepala Desa Simatupang. Penyuluhan dilakukan oleh Tim PKM dan pemeriksaan IVA Test dilakukan oleh 
Tim PKM sebanyak 2 (dua) orang, Bidan Koordinator Puskesmas Muara, Bidan Desa Simatupang. Berdasarkan hasil anamnesa dan pemeriksaan IVA Test didapatkan hasil sebagai berikut :

Tabel 1 Karakteristik Karakteristik Ibu di Desa Simatupang Kecamatan Muara Kabupaten Tapanuli Utara Tahun

\begin{tabular}{cccc}
\hline NO & Karakteristik & F & \% \\
\hline 1 & Usia & & \\
& $20-30$ & 21 & 31,82 \\
& $31-40$ & 28 & 42,42 \\
& $>40$ & 17 & 25,76 \\
2 & Pendidikan & & \\
& Tamat SMP & 2 & 3,03 \\
& Tamat SMA/SMU & 53 & 80,30 \\
& Tamat PT & 11 & 16,67 \\
\hline
\end{tabular}

Tabel 1 menunjukkan bahwa pada usia WUS mayoritas pada usia 31 - 40 tahun dan pendidikan mayoritas SMA/SMU.

Tabel 2 Hasil Pemeriksaaan IVA Test Pada Wanita Usia Subur Di Desa

Simatupang Kecamatan Muara Kabupaten Tapanuli Utara

\begin{tabular}{ccccc}
\hline No & & Hasil & F & \% \\
\hline 1 & Negatif & 51 & 78,79 \\
2 & Dicurigai & 14 & 21,21
\end{tabular}

Tabel 2 menunjukkan bahwa hasil pemerikaan IVA Test terdapat WUS yang dicurigai kanker serviks sebanyak 14 orang $(21,21 \%)$

\section{Pembahasan}

Usia individu yang terhitung mulai saat dilahirkan sampai berulang tahun. Semakin cukup umur, tingkat kematangan dan kekuatan seseorang akan lebih matang dalam berfikir dan bekerja. Hal ini akan sebagai dari pengalaman dan kematangan jiwa. Hasil penelitian menunjukkan ada hubungan yang signifikan antara umur dengan prilaku pemeriksaan IVA Test. Hal ini dapat terjadi karena 
pengetahuan, dimana secara psikologis seharusnya usia dewasa yang lebih tua lebih banyak melakukan tindakan pencegahan karena merasa lebih rentan terhadap masalah kesehatan.

Karakteriktik WUS pada tabel 1 berdasarkan usia, sebagian besar WUS adalah pada kelompok usia $30-40$ tahun $(42,42, \%)$. Hal ini sejalan dengan teori bahwa semakin tua seseorang maka semakin tinggi risiko terkena kanker serviks. Wanita yang berisiko terkena kanker serviks adalah wanita berusia diatas 35 tahun. Deteksi dini kanker leher rahim dan kanker payudara dilakukan pada kelompok sasaran perempuan 20 tahun ke atas, namun prioritas program deteksi dini di Indonesia pada perempuan usia 30-50 tahun dengan target 50\% perempuan sampai tahun 2019.

Pendidikan mempengaruhi proses belajar, makin tinggi pendidikan seseorang, makin mudah orang tersebut menerima informasi. Dengan pendidikan tinggi, maka seseorang akan cenderung untuk mendapatkan informasi, baik dari orang lain maupun media massa. Karakteriktik WUS pada tabel 1 berdasarkan pendidikan mayoritas SMA/SMU (80,30\%).

Hal ini sesuai dengan teori bahwa pendidikan adalah salah satu faktor yang sangat mempengaruhi perilaku masyarakat. Semakin tinggi tingkat pendidikan seseorang semakin mudah orang tersebut menerima informasi sehingga makin banyak pengetahuan yang dimiliki. Mereka akan mengerti dan memahami akan pentingnya melakukan pemeriksaan IVA Test dan sebaliknya apabila pendidikan masyarakat rendah maka makin sedikit pengetahuan yang dimiliki, sehingga mereka akan mengabaikan dan tidak mengerti akan pentingnya pelayanan kesehatan khususnya pada pemeriksaan IVA Test. Pengetahuan tentang metode IVA Test sebagai deteksi dini kanker serviks penting ntuk dimiliki oleh setiap wanita usia subur agar memiliki kemauan dan kesadaran ntuk melakukan tes IVA Test. 
Dari tabel 2 di atas dapat dilihat bahwa hasil pemeriksaan IVA test terhadap WUS di Desa Simatupang Kecamatan Muara adalah sebagai berikut: hasil pemeriksaan dicurigai mengalami gejala kanker serviks $(21,21 \%)$ dan negatif $78,78 \%$ dari jumlah total peserta yang diperiksa yaitu 66 orang. Peserta yang dicurigai (erosi dan infeksi) diberi pengobatan dan dianjurkan untuk periksa rutin sampai sembuh.

\section{SIMPULAN}

Simpulan dari hasil kegiatan pengabdian masyarakat tentang deteksi dini kanker serviks adalah dari hasil pemeriksaan iva test pada ibu - ibu di Desa Simatupang Kecamatan Muara adalah hasil pemeriksaan dicurigai mengalami gejala kanker serviks $(21,21 \%)$ dan negatif $78,78 \%$ dari jumlah total peserta yang diperiksa yaitu 66 orang.

\section{UCAPAN TERIMAKASIH}

Ibu dengan hasil IVA Test yang dicurigai mengalami gejala kanker serviks, untuk selanjutnya dirujuk ke Puskesmas Muara melalui Bidan Desa Simatupang untuk diberikan pengobatan dan dianjurkan untuk periksa rutin sampai sembuh. Terimakasih kepada seluruh pihak yang telah membantu terlaksananya PKM ini dengan lancar khususnya kepada WUS Desa Simatupang Kecamatan Muara Kabupaten Tapanuli Utara. 


\section{DAFTAR PUSTAKA}

Agusdrajat, Buku saku pencegahan Kanker leher rahim; www.wordpress.com (pdf) Direktorat Pengendalian Penyakit tidak menular Direktorat Jenderal PP \& PL Departemen Kesehatan RI 2009.

Akinyemiju, T. F, Jasmine, M. D, \& Paula, L. P. (2015). Health Care Access Dimensions and Cervical Cancer Screening in South Africa : Analysis of the World Health Survey. BioMed Central Public Health, (15:382), 1-8. https://doi.org/10.1186/ s12889-015$1686-5$

European Society Gyncology Oncology (ESGO), 2011, Algorithms for management of cervical cancer.

Komite Penanggulangan Kanker Nasional, 2017, Panduan Penatalaksanaan Kanker Serviks, Jakarta, Kementerian Kesehatan RI.

Kementerian Kesehatan RI, 2013, Riset Kesehatan Dasar, Jakarta.

, 2015, Rencana Strategis Kemenkes RI Tahun 2015-2019, Jakarta, Kementerian Kesehatan RI.

Pedoman Pelayanan Medik Kanker Ginekologi,2011, Kanker Serviks, 20ed.

Pusdatin Kemenkes RI, 2016, Bulan Peduli Kanker Payudara (Oktober 20), Jakarta, Kementerian Kesehatan RI. 